\title{
Tumor infiltrating lymphocytes: The regulator of melanoma evolution (Review)
}

\author{
MIHAELA ANTOHE ${ }^{1,2}$, ROXANA IOANA NEDELCU ${ }^{1,2}$, LUCIANA NICHITA $^{3}$, CRISTIANA GABRIELA POPP ${ }^{3}$, \\ MIRELA CIOPLEA $^{3}$, ALICE BRINZEA ${ }^{1,4}$, ANASTASIA HODOROGEA ${ }^{1,5}$, ANDREEA CALINESCU $^{5,6}$, \\ MIHAELA BALABAN ${ }^{2,7}$, DANIELA ADRIANA ION ${ }^{1}, \mathrm{CARMEN} \mathrm{DIACONU}^{8}, \mathrm{CORALIA} \mathrm{BLEOTU}^{8}$, \\ DANIEL PIRICI ${ }^{9}$, SABINA ANDRADA ZURAC ${ }^{3,10}$ and GABRIELA TURCU ${ }^{2,5,11}$
}

\author{
${ }^{1}$ Department of Pathophysiology, 'Carol Davila' University of Medicine and Pharmacy, 050474 Bucharest; \\ ${ }^{2}$ Department of Dermatology, Derma $360^{\circ}$ Clinic, 011274 Bucharest; ${ }^{3}$ Department of Pathology, Colentina Clinical Hospital, \\ 021103 Bucharest; ${ }^{4}$ National Institute for Infectious Diseases 'Prof. Dr. Matei Balș', Ambulatory Service, 021105 Bucharest; \\ ${ }^{5}$ Department of Dermatology, Colentina Clinical Hospital, 021103 Bucharest; Departments of ${ }^{6}$ Physiology and \\ ${ }^{7}$ Biochemistry, 'Carol Davila' University of Medicine and Pharmacy, 050474 Bucharest; ${ }^{8}$ Department of Cellular and \\ Molecular Pathology, 'Stefan S. Nicolau' Institute of Virology, 030304 Bucharest; ${ }^{9}$ Department of Pathology, \\ University of Medicine and Pharmacy of Craiova, 200349 Craiova; Departments of ${ }^{10}$ Pathology and \\ ${ }^{11}$ Dermatology, 'Carol Davila' University of Medicine and Pharmacy, 050474 Bucharest, Romania
}

Received August 9, 2018; Accepted September 27, 2018

DOI: $10.3892 / \mathrm{ol} .2019 .9940$

\begin{abstract}
Melanoma is the most severe type of skin cancer and its incidence has increased in the last decades. In the United States, it is the 6th most common cancer in both men and women. Prognosis for patients with melanoma depends on the stage of the disease at the time of diagnosis and it can be influenced by the immunologic response. Melanoma has been historically considered an immunogenic malignancy. It often contains great amount of immune cells (different subsets of T-cells, dendritic cells, macrophages, neutrophils, mast cells, B lymphocytes), which may reflect a continuous intercommunication between host and tumor. It is not established if tumor-infiltrating lymphocytes (TILs) are induced by tumor cells or by other components of the microenvironment or when they are a host direct immunologic reaction. It has been observed that in many cases, the presence of a dense TIL is associated with good prognosis. The pattern and activation state of the cells which constitute TIL is variable and modulates
\end{abstract}

Correspondence to: Dr Roxana Ioana Nedelcu, Department of Pathophysiology, 'Carol Davila' University of Medicine and Pharmacy, 1 Calistrat Grozovici Road, 050474 Bucharest, Romania E-mail: roxana.nedelcu@umfcd.ro

Abbreviations: TILs, tumor-infiltrating lymphocytes; CTLA4, cytotoxic T lymphocyte antigen 4; PD-1, programmed cell death-1; PD-L1, programmed death-ligand 1; TSAs, tumor-specific antigens; TAAs, tumor-associated antigens; TCR, T-cell receptor; APCs, antigen-presenting cells

Key words: melanoma, immunogenic tumor, dendritic cells, immunoediting the clinical outcome. An important step in the understanding of tumor immunobiology is the analysis of the populations and subsets of immune cells that form TIL. Besides its prognostic significance, after approval of cytotoxic $\mathrm{T}$ lymphocyte antigen 4, programmed cell death-1 and programmed death-1 ligand antibodies for the treatment of melanoma, the assessment of immune infiltrate composition has become even more captivating, as it could provide new target molecules and new biomarkers for predicting the effect of the treatment and disease outcome in patients treated with immunotherapy. In this review we discuss current state of knowledge in the field of immune cells that infiltrate melanoma, resuming the potential of TIL components to become prognostic markers for natural evolution, for response to drugs or valuable targets for new medication.

\section{Contents}

1. Introduction

2. Melanoma: An immunogenic tumor

3. Tumor infiltrating lymphocytes as a prognostic and predictive factor in melanoma

4. The tumor microenvironment and tumor infiltrating lymphocytes

5. Immunoediting

6. Discussion

\section{Introduction}

Despite the advances made over the past decades in the research area, melanoma remains the most aggressive type of skin cancer. It shows an alarming increasing incidence, and 
in the United States it was registered as the 6th most common type of cancer in both sexes (1). Prognosis for patient with melanoma depends on the stage of the disease at the time of diagnosis. The unpredictable outcome is governed by a multitude of complex reactions between the tumor and the immune system of the host $(2,3)$.

Melanoma has historically been considered an immunogenic malignancy as it contains great amount of immune cells (different subsets of T-cells, dendritic cells, macrophages, neutrophils, mast cells, B lymphocytes) and the presence of a dense tumor infiltrating lymphocytes (TILs) is associated with good prognosis $(3,4)$. The analysis of the populations and subsets of immune cells that form TIL and their interaction with tumor cells led to the development of antibodies against immune check point inhibitors, with remarkable clinical results/outcome and new molecules are under investigation $(5,6)$.

Currently, diagnosis, prognosis and therapy are based on the TNM staging system which takes into account clinico-pathological risk factors: tumor thickness, ulceration, mitotic rate, sentinel lymph node status and presence of metastases (7). But AJCC classification cannot predict the distinct progression and different responses to treatment of melanomas classified at the same stage, showing the urgent need to decipher new parameters to better stratify them, to identify which patient needs a certain pathway inhibitor and in what moment, according to his particular risk. Profound evaluation of TIL can enlighten the way to new and more effective solutions for melanoma patients.

\section{Melanoma: An immunogenic tumor}

It is known for many years that melanoma is an immunogenic tumor and the use of this particularity in the development of new therapeutic strategies has been attempted. Several clinical aspects support this theory: partial or total regression of primary melanomas, depigmentation areas within the tumor or sometimes depigmentation ring ('halo') around the primary melanomas or cutaneous metastases, and the development of vitiligo-like depigmentation in patients with melanoma, associated with a good prognosis $(4,8)$.

The histopathological evidence of lymphocytes and other mononuclear cells in association with melanoma cells prove the involvement of the immune system. Although it was initially considered the cause of the malignancies, nowadays the debate is to establish if TIL are induced by tumor cells or by other components of the microenvironment or whether they are a host direct immunologic reaction (2). It has been observed that in most situations, the presence of a dense TIL is associated with better prognosis or a better survival rates $(9,10)$.

\section{Tumor infiltrating lymphocytes as a prognostic and predictive factor in melanoma}

Over time, histopathological parameters in primary cutaneous melanoma were subject to numerous studies regarding prognosis of the disease. Thus, multivariate analyzes have shown that tumor thickness and ulceration are the most important prognostic predictors in localized disease. Increased evidence suggests that tumor TIL represent an independent prognostic marker (9-11).

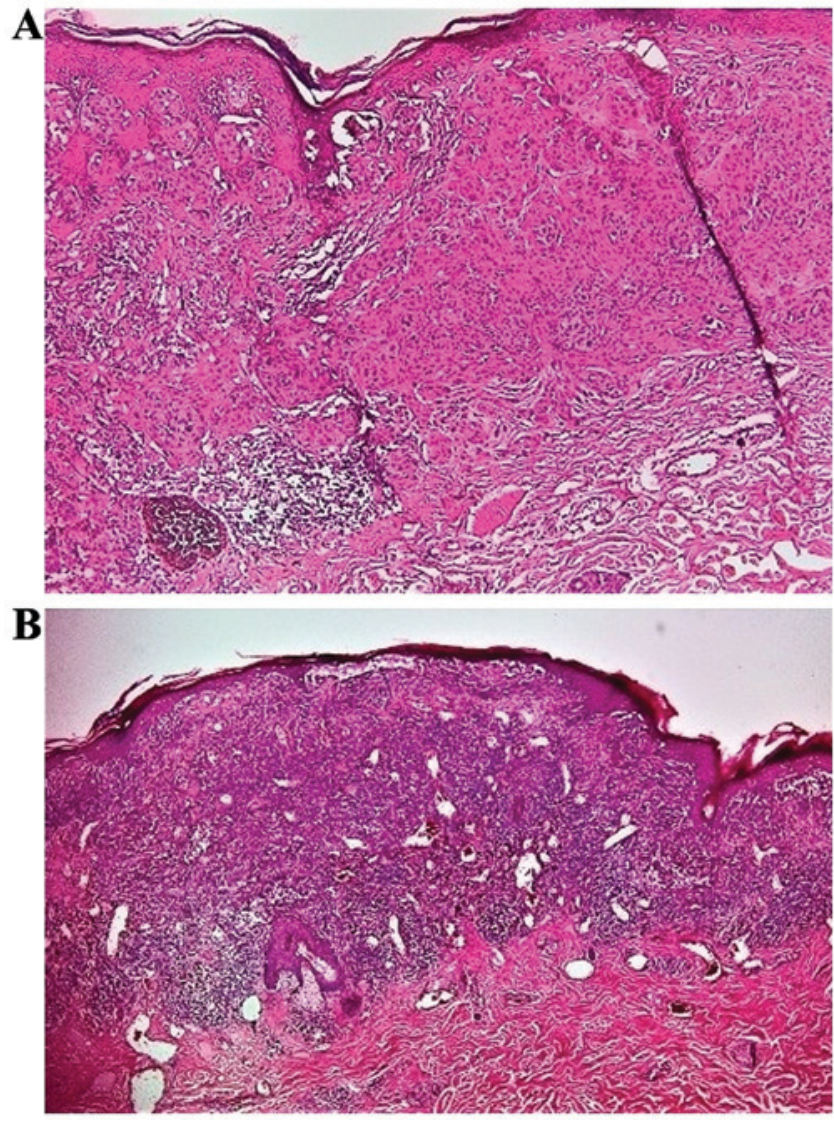

Figure 1. Tumor infiltrating lymphocytes. (A) Non-brisk TIL (H\&E, x100); (B) Brisk TIL with intratumoral and continuous peritumoral distribution (H\&E, x40).

According to Clark et al (10), TIL infiltrate can be classified as: absent, non-brisk or brisk and this quantification is still accepted by most authors (12). TIL are considered absent when leukocytes are absent or if they are present, they do not infiltrate the tumor (12). Non-brisk TIL represents the infiltrate distributed only focally and not along the entire base of the invasive component (Fig. 1A). Brisk TIL is defined by lymphocytes that infiltrate diffusely the entire invasive component or infiltrating across the entire base of vertical growth phase (Fig. 1B) $(12,13)$.

Numerous studies have repeatedly shown the density and the pattern of distribution of TIL in the vertical growth phase of primary melanomas has prognostic significance, but not in the radial growth phase $(9,10,14,15)$.

Hussein et al have shown a progressive increase in TIL during tumorigenesis in melanocytic lesions, this being interpreted as an effect of increasing tumor antigenicity. Interestingly, TIL decrease in metastatic melanoma reflects defence breakdown (16).

Moreover, it can be seen as independent predictive factor for sentinel lymph node status (2). It was observed that the prognosis of patients with brisk inflammatory infiltrate was significantly better than that of patients with non-brisk or absent TIL and correlated with prolonged disease-free and overall survival $(9,10)$.

Due to its reported prognostic significance, some authors consider that this parameter should be included and quantified in the histological report (2). 


\section{The tumor microenvironment and tumor infiltrating lymphocytes}

Tumor mass is made up of tumor cells but also stromal cells that enable them to live and grow, endothelial cells, infiltrating leukocytes, fibroblasts and a complex extracellular matrix that form the local tumor environment (17).

TIL are a polymorphic group that is composed mainly by effector $\mathrm{T}$ lymphocytes, regulatory $\mathrm{T}$ lymphocytes, natural killer (NK) cells, dendritic cells and macrophages (18). The distribution, the density, the profile and the activation state of the cells which constitute TIL can be variable and modulate the clinical outcome.

Based on the current information, for a better understanding of the phenomena, we will present the scenario of the development of TIL, the roles of its components and how they can modulate the progression of the disease, with the final goal to be able to develop new immunotherapeutic strategies.

Melanoma antigens. The first step in the initiation of the host immune response in primary cutaneous melanoma is recognition of the antigens that will induce inflammatory intratumoral infiltrate (19).

Tumor antigens in melanoma are of two types: specific antigens that are expressed by tumor cells (tumor-specific antigens, TSAs) and tumor associated antigens (TAAs), which are predominantly found in the tumor cells. TSA are also called 'neoantigens' because they are newly formed antigens and they are not found in the normal human genome. TSA exert high immunogenicity and induce T-lymphocytes that are not affected by central tolerance and maintain for a period of time an efficient adaptative anti-tumor activity. There is an extremely large number of possible mutations, so that each patient tumor is unique, tumors from the same patient can be different, and there is also intratumoral heterogeneity (20). On the other hand, TAA are mainly found in tumor cells but can also be expressed by normal melanocytes and most of them are of intracellular protein origin. Most often melanoma cells express only MHC class I and do not express MHC class II molecules. TAA do not induce an ideal cytotoxic T-cell reaction and generate reduced formation of tumor-specific $\mathrm{CD}^{+}$and antibodies $(4,11,21)$.

Malignant tumor cells can employ different stratagem to avoid T-cell intervention. In some cases, tumor cells can reduce their expression of TAA or they can produce chemokines and cytokines with immunosuppressive consequences (22-25).

Dendritic cells (DCs). DC are among the first cells to reach the tumor, recognize tumor antigens and play a pivotal role in the initiation and regulation of both innate and adaptive immunity (17). They are the most potent antigen-presenting cells (APCs) and after processing of tumor-associated antigens, they induce a specific antitumor response by cross-presentation of antigens to $\mathrm{CD}^{+} \mathrm{T}$ lymphocytes by $\mathrm{MHC}$ class I molecules and to $\mathrm{CD}^{+}$by $\mathrm{MHC}$ class II molecules (26). In order to obtain a potent anti-tumoral immune response of $\mathrm{T}$ lymphocytes, the antigen presentation must be efficiently done by mature dendritic cells. DC can additionally contribute to the cytotoxic immune reaction directly and by activating NK cells (27).
DC from the skin, Langerhans cells, dermal DC and plasmacytoid DC may exhibit different phenotypes, with dualistic functions (28). In the tumor microenvironment, mediators released by tumor cells or tumor-associated macrophages (TAMs) such as IL-8, IL-10, TGF- $\beta 1$ and VEGF limit normal DC maturation, in an attempt to evade host immune response $(20,29,30)$.

DCs in the immature state fail to properly stimulate T-cells. On the other hand, by favoring proliferation of regulatory T-cells, they block T-cell responses. In this way they are mediators of immune tolerance despite immune activation, a phenomenon described in patients with melanoma in 1997 by Enk et al (31). Immature/tolerogenic DC regulate tumor angiogenesis and favor an active tumor growth (32). This proangiogenic effect is no longer operative with DC maturation. The maturation process of dendritic cells is dependent on factors encountered in the tumor microenvironment (33).

Mature DC are distributed mainly peritumorally and their density, together with the activation status of T lymphocyte, correlated with melanoma tumor thickness and patient's survival, making Kobayashi et al and Simonetti et al to recommend the use of these parameters as a predictor of treatment response in patients treated with immunotherapy $(34,35)$.

An adequate number of mature DC in tumor area can eliminate malignant cells (36). Lotze showed that infiltration with mature DC in primary tumors is associated with fewer metastases and better prognosis (37).

Interaction of APC and T lymphocyte-immune checkpoints. In an ideal situation, antigen-presenting cells lead to activation of effector memory T-cells in the lymph nodes that mediate antitumor effects at tumor site, producing new antigens from destroyed tumor cell and creating a tumor-immunity cycle $(2,38)$.

After recognizing the antigen presented by APC, T-cells require several signals for full activation. The first signal depends on the antigen and is represented by MHC I or MHC II complexed with the presented peptide, binding to the T-cell receptor (TCR) (39). Insufficiently presented antigen on APC cannot activate T-cells and induce immunologic ignorance (40).

Cell adhesion molecules are responsible for maintaining the connection between the two cells and allow as many TCRs on the T-cell as possible to become activated (41). In metastatic disease a diversity of TCR was observed between different sites that can have different clinical evolution, explained by the selection of T-cells directed against different tumor antigens or against different epitopes from the same antigen (38).

The second signal of activation requires specific interaction between T-cell receptors from their ligands and APC (from CD28/B7 family), and is antigen-independent (39). These receptors are of two types: co-stimulators or co-inhibitors. Many ligands can bind to multiple receptors, of each type (42).

The interplay between costimulatory receptors and their ligand completely activate T-cells and induce production of tumor-specific T-cells (43).

In normal conditions, co-inhibitor receptors [programmed cell death-1 (PD-1), cytotoxic T lymphocyte antigen-4 (CTLA-4), B and T lymphocyte attenuator (BTLA) and T-cell immunoglobulin and mucin domain-3 (TIM-3), known as 'immune checkpoint molecules', and their ligands (respectively, 
programmed death-ligand 1 (PD-L1) or PD-L2, CD80 or CD86, herpesvirus entry mediator (HVEM) and galectin 9], inhibit T-cell activity and are involved in maintaining self-tolerance and modulating the intensity and duration of an anti-infectious immune response $(30,42)$. Activation of inhibitory immune checkpoints by cancer cells shield them from the immune attack and allow them to proliferate further $(38,44)$.

APC T-cell interaction can be mediated also by tumor necrosis factor (TNF) family members and their receptors, by the soluble cytokines from the microenvironment (TGF- $\beta$, IL-1, IL-10, IL-12, IL-18) and by immune-inhibitory molecules, metabolic enzymes that deprive lymphocytes of necessary aminoacids [indoleamine 2,3-dioxygenase (IDO)] that can be new therapeutic targets $(42,45,46)$.

Thus, it has been observed that the immune system has a dual role, by modifying the interactions between co-stimulatory and co-inhibitory signals. On the one hand, it can control malignant cells but on the other hand, it may favor tumor progression (47).

Tymphocytes. TIL include different subsets of lymphocytes, in different proportions, adjusted by cytokines secreted by tumor cells or other residents: $\mathrm{CD}^{+} \mathrm{T}$-cells, $\mathrm{CD} 4^{+} \mathrm{T}$-cells, NK cells and B-cells $(48,49)$. T lymphocytes have a major role in the antitumor immune responses and are the dominant elements in the tumor microenvironment.

TSA generate highly sensitive and specific $\mathrm{CD}^{+} \mathrm{T}$ recognition and data suggest that TIL may specifically target TSA $(50,51)$. TAA can induce tumor-specific $\mathrm{CD}^{+}, \mathrm{CD}^{+}$ T-cells and antibodies against TAA (30).

CD8 effector T-cells (or cytotoxic T-cells) inhibit tumor proliferation, either through direct cytolytic action on tumor cells or by releasing interferon (IFN) $-\gamma$ and TNF- $\alpha(50,52)$. Therefore, a large infiltration of $\mathrm{CD}^{+} \mathrm{T}$-cells in the tumor is related to a good prognosis in patients with melanoma (53). Protracted antigen exposure can cause tumor antigen-specific T-cells 'exhaustion'. PD-1 and TIM-3 have been considered immunohistochemical markers for 'exhaustion' (4). Based on the balance between co-stimulatory and co-inhibitory signals from the micro-environment, CD8 T-cells may exert different functional states (54).

There are four main types of $\mathrm{CD}^{+}{ }^{+} \mathrm{T}$-cells ( $\mathrm{T}$ helper cells), with distinct properties and in variable percentage: Th1, Th2 Th17, and Treg.

Th1, Th2 help antitumor fight by stimulating the activity of $\mathrm{CD}^{+}$T-cells through mediators such as IFN- $\gamma$, TGF- $\beta$ or IL-2 $(55,56)$. Th1 can also favor activation of macrophages and maturation of dendritic cells, while Th2 can use cytotoxic weapons of eosinophils $(57,58)$. A consistent intratumoral infiltration of $\mathrm{CD}^{+} \mathrm{T}$-cells and Th1 cells is correlated with favorable prognosis and better survival in most human cancers (59).

Th17 cells have two antagonist forms: in certain cytokine milieu can convert to Th1 characteristics and exert antitumor effects, while in other conditions can switch to regulatory T-cells characteristics and induce tumor progression (60).

Regulatory T-cells (CD25/FoxP3 suppressive T-cells, Treg) are a subtype of T-cells with a key role in preventing autoimmune diseases. Their presence in the tumor microenvironment inhibits the antitumor immune responses. They are attracted to the tumor microenvironment by chemokines secreted by tumor cells and macrophages. Tregs are activated after recognizing TAA released from destroyed tumor cells and then specifically suppress the activation of TAA-specific effector T-cells and the efficient tumor cell destruction by various mechanisms (IL-10, TGF- $\beta$ ) (41,61). Moreover, Treg can suppress the action of several types of immune system cells such as $\mathrm{CD}^{+} \mathrm{T}$-cells, NK cells, B cells and APC (62).

There are few studies done on the prognostic role of Treg in melanoma. Some have noted the association between the presence of a high Tregs infiltrate with the local recurrence of the disease, fast tumor progression, a higher metastasis rate in the sentinel lymph node, but without any association with tumor thickness or patient survival (63-66).

It is considered that ratios between different subsets of T-cells can provide more accurate information on the local immune balance and CD8/FoxP3 (effector/regulatory) ratio and CD8/CD4 (effector/helper) ratio are the most commonly used (67). To skip from immune attack, tumor cells suppress tumor-specific T effector and induce immunosuppressive Treg cells, thus reducing $\mathrm{CD} 8$ /Treg ratios. In patients treated with combination checkpoint therapy, CD8/Treg ratios increased and was associated with improving survival in melanoma (68).

NK cells. NK are effector cells of the innate immune system and play an essential role in cancer immune surveillance due to their ability to destroy tumor cells independent of MHC or previous activation (69).

NK also participate in regulation of adaptive immune reactions through interactions with DCs, that activate NK cells and determine a potent cytotoxic immune response against tumor cells (27).

Tumor cells may defeat NK by releasing TGF- $\beta$, by low antigenicity expression or by increased MHC I expression $(33,69-71)$. Tregs can also contribute by rivaling with NK for IL-2 (30). The activation state of NK cells is modulated by activating and inhibitory receptors.

The prognostic role of NK cell infiltration in melanoma has not been evaluated, but they seem to limit the development of hematogenous metastases (28).

B cells. B cells represent $15-20 \%$ of all infiltrating lymphocytes $(16,30,66)$. The exact roles of tumor-infiltrating B cells in antitumoral immune response are not defined. A trend for their higher prevalence was observed in thicker tumors and an increased density of B lymphocytes infiltrating primary cutaneous melanomas was associated with reduced risk of distant metastases and longer survival $(28,72)$ The roles of plasma cells are even less understood. Bosisio et al recently reported a significantly worse survival in primary melanomas with clusters of plasma cells compared to a better outcome in the cases with sparse plasma cell infiltrate. Most plasma cells were polyclonal, expressing predominantly IgG and IgA (73).

Macrophages. TAMs are a heterogeneous group of cells with antigen-presenting capacity and represent the predominant inflammatory cells of the tumor infiltrating lymphocytes. They are found in all stages of the tumor progression (30). Based on the signals from microenvironment, macrophages can render antagonist functional characteristics. 
M1 macrophages, the classical type, have high antigenpresenting action and also can produce Th1 cytokines and exert antitumor effect (69).

M2 macrophages have a low antigen-presenting activity, inhibit $\mathrm{CD}^{+}$T-cell and NK cell activity, stimulate switch to Th2 and Treg predominance, stimulate antibody production, angiogenetic effects and favor tumor cell migration $(74,75)$. It is the predominant profile in TAM, induced by products secreted by dendritic cells, Treg lymphocytes and tumor microenvironment. During tumor growth and progression, macrophages convert from M1 to M2 phenotype (29).

Studies have shown correlation between TAM density and tumor thickness and ulceration, but no significant correlation with survival in patients with melanoma (76).

\section{Immunoediting}

All the above cells are players in a complex process of immunoediting. They produce a variety of cytokines, chemokines and growth factors with important roles in adjusting interactions between cells, regulating cell differentiation, activation and functioning of many types of cells (17).

Permanent interactions between the tumor and the immune system can lead to malignant cell elimination, an equilibrium state or malignant cell escape (77). The transition between these phases is adjusted by the immune system status and the activity of the tumor cells. If the innate and the adaptive immune systems successfully remove tumor cells, the elimination is the final stage of immunoediting (77).

In some cases, not all tumor cells can be eliminated, but their proliferation can be handled by the immune system. In this equilibrium state tumor cells remain latent for a variable period of time (78).

Nevertheless malignant cells possess a wide variety of means that in the end enable them to escape from the control of the immune system, starting to proliferate and lead to the appearance of the primary tumors and metastases.

Melanoma cells can passively evade or actively suppress the antitumor immune response through several mechanisms, deceiving and defeating one by one each of the immune system players previously described: i) downregulate TAA $(79,80)$; ii) induce T-cell exhaustion by prolonged TSA exposure (81); iii) express low levels of MHC I (82); iv) evade recognition by NK cells and reduce their cytolytic activity (83); v) induce T-cell apoptosis by Fas-Fas ligand pathway (49); vi) recruit tolerogenic Treg (84); vii) produce inhibitory signaling molecules and induce immunological tolerance $(85,86)$; and viii) express immune checkpoint proteins that shelter them from T-cells or macrophages attack (87). Despite a strong, complex anti-melanoma immune response, melanoma cells use all the tricks to escape without being destroyed $(30,77)$.

\section{Discussion}

Each individual, each organ, and accordingly, each tumor and each metastatic site form the same tumor have distinctive immunologic particularities that are far from being deciphered.

This review wants to bring to attention the multiple variable that modulate melanoma outcome, starting from
TSA that can be the result of a unique mutation, and induce a specific effector T-cell, which can have a variable activity state, depending on how the antigen was presented, depending on the specific context of either stimulatory or inhibitory receptors, cytokines and chemokines, that can be variable in time and favor accumulation of different proportions of NK, macrophages or Treg, with specific phenotypes and functions. The cumulative effect of these antagonist forces can be either successful elimination of tumor cells, temporary control or evasion.

Several therapeutic approaches have been tested, addressing different steps involved in melanomagenesis, with unsatisfactory results. The new data on the role of the immune system and the mechanism of immune escape led to the development of immune checkpoint inhibitors, that unblock antitumor immunity, considered among the most important medical findings of the recent years, with significant increased survival for patients with stage IV melanoma.

Even if it may represent a photo of a certain moment in tumor evolution movie, analyzing the profile of the immune cells from TIL may help understanding of tumor immunobiology and, considering the already proved prognostic significance, it may help to identify potential biomarkers for a better risk stratification, to further devise new weapons, for new targets, for the individual unique melanoma.

\section{Acknowledgements}

Not applicable.

\section{Funding}

This work is partially supported by a grant of Ministry of Research and Innovation, CNCS-UEFISCDI (project no. PN-III-P4-ID-PCE-2016-0641) within PNCDI-III. This work was partially supported by a grant of Romanian Ministry of Research and Innovation, CCCDI-UEFISCDI (project no. 61PCCDI/2018 PN-III-P1-1.2-PCCDI-2017-0341) within PNCDI-III.

\section{Availability of data and materials}

Not applicable.

\section{Authors' contributions}

MA, RIN, GT contributed to the conception and design of the study, interpretation of the data, and revising it critically for important intellectual content. LN, CGP, MC, SAZ, AB, AH, $\mathrm{AC}, \mathrm{MB}$ were responsible for the acquisition and interpretation of the data, writing and drafting the study. DAI, CD, CB, DP had substantial contributions to the interpretation and analysis of the data, drafting the study and revising it critically for important intellectual content. All authors read and approved the final version of the manuscript.

\section{Ethics approval and consent to participate}

Not applicable. 


\section{Patient consent for publication}

Not applicable.

\section{Competing interests}

The authors declare that they have no competing interests.

\section{References}

1. Sosman JA: Patient education: Melanoma treatment; advanced or metastatic melanoma (Beyond the Basics). Atkins MB and Vora SR (eds). https://www.uptodate.com/contents/melanomatreatment-advanced-or-metastatic-melanoma-beyond-the-basics.

2. Azimi F, Scolyer RA, Rumcheva P, Moncrieff M, Murali R, McCarthy SW, Saw RP and Thompson JF: Tumor-infiltrating lymphocyte grade is an independent predictor of sentinel lymph node status and survival in patients with cutaneous melanoma. J Clin Oncol 30: 2678-2683, 2012.

3. Neagu M: The immune system: A hidden treasure for biomarker discovery in cutaneous melanoma. Adv Clin Chem 58: 89-140, 2012

4. Mukherji B: Immunology of melanoma. Clin Dermatol 31: 156-165, 2013.

5. Dummer R, Hauschild A, Lindenblatt N, Pentheroudakis G and Keilholz U: Cutaneous melanoma: ESMO clinical practice guidelines for diagnosis, treatment and follow-up. Ann Oncol 26: 126-132, 2015.

6. Turcu G, Nedelcu RI, Ion DA, Brînzea A, Cioplea MD, Jilaveanu LB and Zurac SA: CEACAM1: Expression and role in melanocyte transformation. Disease Markers 2016: 9406319, 2016.

7. Coit DG, Thompson JA, Algazi A, Andtbacka R, Bichakjian CK, Carson WE, Daniels GA, DiMaio D, Ernstoff M, Fields RC, et al: Melanoma, Version 2.2016, NCCN Clinical Practice Guidelines in Oncology. J Natl Compr Canc Netw 14: 450-473, 2016.

8. Nedelcu RI, Zurac SA, Brînzea A, Cioplea MD, Turcu G, Popescu R and Ion DA: Morphological features of melanocytic tumors with depigmented halo: review of the literature and personal results. Rom J Morphol Embryol 56: 659-663, 2015.

9. Clemente CG, Mihm Jr MC, Bufalino R, Zurrida S, Collini P and Cascinelli N: Prognostic value of tumor infiltrating lymphocytes in the vertical growth phase of primary cutaneous melanoma. Cancer 77: 1303-1310, 1996.

10. Clark WH, Elder DE, Guerry D, Braitman LE, Trock BJ, Schultz D, Synnestvedt M and Halpern AC: Model predicting survival in stage I melanoma based on tumor progression. J Natl Cancer Inst Dec 81: 1893-1904, 1989.

11. Lee N, Zakka LR, Mihm MC and Schatton T: Tumour-infiltrating lymphocytes in melanoma prognosis and cancer immunotherapy. Pathology 48: 177-187, 2016.

12. Busam KJ, Antonescu CR, Marghoob AA, Nehal KS, Sachs DL, Shia J and Berwick M: Histologic classification of tumor-infiltrating lymphocytes in primary cutaneous malignant melanoma: A study of interobserver agreement. Am J Clin Pathol 115: $856-860,2001$

13. Spatz A, Batist G and Eggermont AM: The biology behind prognostic factors of cutaneous melanoma. Curr Opin Oncol 22: 163-168, 2010.

14. Tuthill RJ, Unger JM, Liu PY, Flaherty LE and Sondak VK: Risk assessment in localized primary cutaneous melanoma: A southwest oncology group study evaluating nine factors and a test of the Clark logistic regression prediction model. Am J Clin Pathol 118: 504-511, 2002.

15. Elder DE, Guerry D, Vanhorn M, Hurwitz S, Zehngebot L, Goldman LI,LaRossa D, Hamilton R, Bondi EE and Clark WH Jr: The role of lymph node dissection for clinical stage I malignant melanoma of intermediate thickness (1.51-3.99 mm). Cancer 56: 413-418, 1985.

16. Hussein MR, Elsers DA, Fadel SA and Omar AE: Immunohistological characterisation of tumour infiltrating lymphocytes in melanocytic skin lesions. J Clin Pathol 59: 316-324, 2006.

17. Shurin MR, Shurin G V, Lokshin A and Ferris RL: Intratumoral cytokines/chemokines/growth factors and tumor infiltrating dendritic cells: friends or enemies? Cancer Metast Rev 25: 333-356, 2006.

18. Mantovani A, Allavena P, Sica A and Balkwill F: Cancer-related inflammation. Nature 454: 436-444, 2008.
19. Van Der Bruggen P, Zhang Y, Chaux P, Stroobant V, Panichelli C, Schultz ES, Chapiro J, Van Den Eynde BJ, Brasseur F and Boon T: Tumor-specific shared antigenic peptides recognized by human T-cells. Immunol Rev 188: 51-64, 2002.

20. Gerlinger M, Rowan AJ, Horswell S, Larkin J, Endesfelder D, Gronroos E, Martinez P, Matthews N, Stewart A, Tarpey P, et al: Intratumor heterogeneity and branched evolution revealed by multiegion sequencing. N Engl J Med 366: 883-892, 2012

21. Durrant L and Ramage J: Development of cancer vaccines to activate cytotoxic T lymphocytes. Expert Opin Biol Ther 5: $555-563,2005$.

22. Ferrone S and Marincola FM: Loss of HLA class I antigens by melanoma cells: molecular mechanisms, functional significance and clinical relevance. Immunol Today 16: 487-494, 1995.

23. Kageshita T, Hirai S, Ono T, Hicklin DJ and Ferrone S: Downregulation of HLA class I antigen-processing molecules in malignant melanoma. Am J Pathol 154: 745-754, 1999.

24. Al-Batran SE, Rafiyan MR, Atmaca A, Neumann A, Karbach J, Bender A, Weidmann E, Altmannsberger HM, Knuth A, et al: Intratumoral T-cell infiltrates and $\mathrm{MHC}$ class I expression in patients with stage IV melanoma. Cancer Res 65: 3937-3941, 2005.

25. Clancy $\mathrm{T}$ and Hovig E: Profiling networks of distinct immune-cells in tumors. BMC Bioinformatics 17: 1-15, 2016.

26. Schiavoni G, Gabriele L and Mattei F: The tumor microenvironment: a pitch for multiple players. Front Oncol 3: 2013. doi: 10.3389/fonc.2013.00090.

27. Tel J, Anguille S, Waterborg CEJ, Smits EL, Figdor CG and de Vries IJM: Tumoricidal activity of human dendritic cells. Trends Immunol 35: 38-46, 2014.

28. Ladányi A: Prognostic and predictive significance of immune cells infiltrating cutaneous melanoma. Pigment Cell Melanoma Res 28: 490-500, 2015.

29. Vitale M, Cantoni C, Pietra G, Mingari MC and Moretta L: Effect of tumor cells and tumor microenvironment on NK-cell function. Eur J Immunol 44: 1582-1592, 2014.

30. Muenst S, Läubli H, Soysal SD, Zippelius A, Tzankov A and Hoeller S: The immune system and cancer evasion strategies: Therapeutic concepts. J Intern Med 279: 541-562, 2016.

31. Enk AH, Jonuleit H, Saloga J and Knop J: Dendritic cells as mediators of tumor-induced tolerance in metastatic melanoma. Int J Cancer 73: 309-316, 1997.

32. Fainaru O, Almog N, Yung CW, Nakai K, Montoya-Zavala M, Abdollahi A, D'Amato R and Ingber DE: Tumor growth and angiogenesis are dependent on the presence of immature dendritic cells. FASEB J 24: 1411-1418, 2010.

33. Da Cunha A, Michelin MA and Murta EF: Pattern response of dendritic cells in the tumor microenvironment and breast cancer. World J Clin Oncol 5: 495-502, 2014.

34. Kobayashi M, Suzuki K, Yashi M, Yuzawa M, Takayashiki N and Morita T: Tumor infiltrating dendritic cells predict treatment response to immmunotherapy in patients with metastatic renal cell carcinoma. Anticancer Res 27: 1137-1141, 2007.

35. Simonetti O, Goteri G, Lucarini G, Rubini C, Stramazzotti D, Lo Muzio L, Biagini D and Offidani A: In melanoma changes of immature and mature dendritic cell expression correlate with tumor thickness:an immunohistochemical study. Int J Immunopathol Pharmacol 20: 325-333, 2007.

36. El Marsafy S, Bagot M, Bensussan A and Mauviel A: Dendritic cells in the skin-potential use for melanoma treatment. Pigment Cell Melanoma Res 22: 30-41, 2009.

37. Lotze MT: Getting to the source: dendritic cells as therapeutic reagents for the treatment of patients with cancer. Ann Surg 226: $1-5,1997$.

38. Boddupalli CS, Bar N, Kadaveru K, Krauthammer M, Pornputtapong N, Mai Z, Ariyan S, Narayan D, Kluger H, Deng Y et al: Interlesional diversity of T-cell receptors in melanoma with immune checkpoints enriched in tissue-resident memory T-cells. JCI Insight 1: e88955, 2016. doi: 10.1172/jci. insight.88955.

39. Pedoeem A, Azoulay-Alfaguter I, Strazza M, Silverman GJ and Mor A: Programmed death-1 pathway in cancer and autoimmunity. Clin Immunol 153: 145-152, 2014.

40. Ochsenbein AF, Klenerman P, Karrer U, Ludewig B, Pericin M, Hengartner $\mathrm{H}$ and Zinkernagel RM: Immune surveillance against a solid tumor fails because of immunological ignorance. Proc Natl Acad Sci 96: 2233-2238, 1999.

41. Inman B, Frigola X, Dong H and Kwon E: Costimulation, coinhibition and cancer. Curr Cancer Drug Targets 7: 15-30, 2007.

42. Pardoll DM: The blockade of immune checkpoints in cancer immunotherapy. Nat Rev Cancer 12: 252-264, 2012. 
43. Mapara MY and Sykes M: Tolerance and Cancer: Mechanisms of tumor evasion and strategies for breaking tolerance. J Clin Oncol 22: 1136-1151, 2004.

44. Ancuceanu R and Neagu M: Immune based therapy for melanoma. Indian J Med Res 143: 135-144, 2016

45. Munn DH and Mellor AL: Indoleamine 2,3-dioxygenase and tumor-induced tolerance. J Clin Invest 117: 1147-1154, 2007.

46. Ochoa AC, Zea AH, Hernandez C and Rodriguez PC: Arginase, prostaglandins, and myeloid-derived suppressor cells in renal cell carcinoma. Clin Cancer Res 13: 721-726, 2007.

47. Becht E, Goc J, Germain C, Giraldo NA, Dieu-Nosjean MC, Sautès-Fridman C and Fridman WH: Shaping of an effective immune microenvironment to and by cancer cells. Cancer Immunol Immunother 63: 991-997, 2014

48. Rosenberg S, Packard B, Aebersold P, Solomon D, Topalian S Toy S, Simon P, Lotze MT, Yang JC, Seipp CA, et al: Use of tumor-infiltrating lymphocytes and interleukin-2 in the immunotherapy of patients with metastatic melanoma. A preliminary report. N Engl J Med 319: 1676-1680, 1988.

49. Cohen PJ, Lotze MT, Roberts JR, Rosenberg SA and Jaffe ES The immunopathology of sequential tumor biopsies in patients treated with interleukin-2. Correlation of response with T-cell infiltration and HLA-DR expression. Am J Pathol 129: 208-216, 1987.

50. Savage P, Leventhal DS, and Malchow S: Shaping the repertoire of tumor-infiltrating effector and regulatory T-cells. Immunol Rev 259: 245-258, 2014

51. Rosenberg SA and Restifo NP: Adoptive cell transfer as personalized immunotherapy for human cancer. Science 348: 62-68, 2015.

52. Fridman WH, Remark R, Goc J, Giraldo NA, Becht E, Hammond SA, Damotte D, Dieu-Nosjean MC and Sautès-Fridman C: The immune microenvironment: A major player in human cancers. Int Arch Allergy Immunol 164: 13-26, 2014.

53. Schlapbach C, Shafighi M, Kiermeir D, Hüsler R and Hunger RE High expression of FOXP3 in primary melanoma is associated with tumour progression. Br J Dermatol 170: 103-109, 2014.

54. Giraldo NA, Becht E, Remark R, Damotte D, Sautès-Fridman C and Fridman WH: The immune contexture of primary and metastatic human tumours. Curr Opin Immunol 27: 8-15, 2014.

55. Kiraz Y, Baran Y and Nalbant A: T-cells in tumor microenvironment. Tumor Biol 37: 39-45, 2016.

56. Yang ZZ and Ansell SM: The tumor microenvironment in follicular lymphoma. Clin Adv Hematol Oncol 10: 810-818, 2012

57. Hung K, Hayashi R, Lafond-Walker A, Lowenstein C, Pardoll D and Levitsky $\mathrm{H}$ : The central role of $\mathrm{CD}^{+} \mathrm{T}$-cells in the antitumor immune response. J Exp Med 188: 2357-2368, 1998.

58. Pereira MC, Oliveira DT and Kowalski LP: The role of eosinophils and eosinophil cationic protein in oral cancer (Review). Arch Oral Biol 56: 353-358, 2011.

59. Fridman WH, Pagès F, Sautès-Fridman C and Galon J: The immune contexture in human tumours: impact on clinical outcome. Nat Rev Cancer 12: 298-306, 2012.

60. Bailey SR, Nelson MH, Himes RA, Li Z, Mehrotra S and Paulos CM: Th17 cells in cancer: the ultimate identity crisis. Front Immunol 5: 1664-3224, 2014

61. Nishikawa H and Sakaguchi S: Regulatory T-cells in cancer immunotherapy. Curr Opin Immunol 27: 1-7, 2014

62. Jiang $X$ and Shapiro DJ: The immune system and inflammation in breast cancer. Mol Cell Endocrinol 382: 673-682, 2014

63. Miracco C, Mourmouras V, Biagioli M, Rubegni P, Mannucci S, Monciatti I, Cosci E, Tosi P and Luzi P: Utility of tumour-infiltrating $\mathrm{CD} 25^{+} \mathrm{FOXP} 3^{+}$regulatory $\mathrm{T}$-cell evaluation in predicting local recurrence in vertical growth phase cutaneous melanoma. Oncol Rep 18: 1115-1122, 2007.

64. Gambichler T, Bindsteiner M, Höxtermann S, Terras S and Kreuter A: Circulating CD4 ${ }^{+} \mathrm{CD} 25$ (high) CD127(low) regulatory T-cells are an independent predictor of advanced melanoma. Pigment Cell Melanoma Res 26: 280-283, 2013.

65. Ma MW, Medicherla RC, Qian M, Vega-Saenz de Miera E, Friedman EB, Berman RS, Shapiro RL, Pavlick AC, Ott PA, Bhardwaj N, et al: Immune response in melanoma: an in-depth analysis of the primary tumor and corresponding sentinel lymph node. Mod Pathol 25: 1000-1010, 2012.

66. Hillen F, Baeten CIM, Van De Winkel A, Creytens D Van Der Schaft DWJ, Winnepenninckx V and Griffioen AW: Leukocyte infiltration and tumor cell plasticity are parameters of aggressiveness in primary cutaneous melanoma. Cancer Immunol Immunother 57: 97-106, 2008.
67. Gooden MJM, De Bock GH, Leffers N, Daemen T and Nijman HW: The prognostic influence of tumour-infiltrating lymphocytes in cancer: A systematic review with meta-analysis. Br J Cancer 105: 93-103, 2011.

68. Twyman-Saint Victor C, Rech AJ, Maity A, Rengan R, Pauken KE, Stelekati E, Benci JL, Xu B, Dada H, Odorizzi PM, et al: Radiation and dual checkpoint blockade activate non-redundant immune mechanisms in cancer. Nature 520 373-377, 2015.

69. Bruno A, Ferlazzo G, Albini A and Noonan DM: A think tank of TINK/TANKs: tumor-infiltrating/tumor-associated natural killer cells in tumor progression and angiogenesis. J Natl Cancer Inst 106: dju200, 2014.

70. Sungur CM and Murphy WJ: Positive and negative regulation by NK cells in cancer. Crit Rev Oncog 19: 57-66, 2014

71. Balsamo M, Vermi W, Parodi M,Pietra G, Manzini C, Queirolo P, Lonardi S, Augugliaro R, Moretta A, Facchetti F, et al: Melanoma cells become resistant to NK-cell-mediated killing when exposed to NK-cell numbers compatible with NK-cell infiltration in the tumor. Eur J Immunol 42: 1833-1842, 2012.

72. Ladányi A, Kiss J, Mohos A, Somlai B, Liszkay G, Gilde K, Fejös Z, Gaudi I, Dobos J, Tímár J: Prognostic impact of B-cell density in cutaneous melanoma. Cancer Immunol Immunother 60: 1729-1738, 2011

73. Bosisio FM, Wilmott JS, Volders N, Mercier M, Wouters J, Stas M, Blokx WA, Massi D, Thompson JF, Scolyer RA, et al: Plasma cells in primary melanoma. Prognostic significance and possible role of IgA. Mod Pathol 29: 347-358, 2016.

74. Allavena P, Sica A, Solinas G, Porta C and Mantovani A: The inflammatory micro-environment in tumor progression: The role of tumor-associated macrophages. Crit Rev Oncol/Hematol 66: $1-9,2008$.

75. Sica A, Schioppa T, Mantovani A and Allavena P: Tumour-associated macrophages are a distinct M2 polarised population promoting tumour progression: Potential targets of anti-cancer therapy. Eur J Cancer 42: 717-727, 2006.

76. Storr SJ, Safuan S, Mitra A, Elliott F, Walker C, Vasko MJ, Ho B, Cook M, Mohammed RA, Patel PM, et al: Objective assessment of blood and lymphatic vessel invasion and association with macrophage infiltration in cutaneous melanoma. Mod Pathol 25: 493-504, 2012

77. Mittal D, Gubin MM, Schreiber RD and Smyth MJ: New insights into cancer immunoediting and its three component phases - elimination, equilibrium and escape. Curr Opin Immunol 27: 16-25, 2014

78. Koebel CM, Vermi W, Swann JB, Zerafa N, Rodig SJ, Old LJ, Smyth MJ and Schreiber RD: Adaptive immunity maintains occult cancer in an equilibrium state. Nature 450: 903-907, 2007.

79. Khong HT, Wang QJ and Rosenberg SA: Identification of multiple antigens recognized by tumor-infiltrating lymphocytes from a single patient: tumor escape by antigen loss and loss of MHC expression. J Immunother 27: 184-190, 2004.

80. Maeurer MJ, Gollin SM, Martin D, Swaney W, Bryant J, Castelli C, Robbins P, Parmiani G, Storkus WJ, Lotze MT: Tumor escape from immune recognition: lethal recurrent melanoma in a patient associated with downregulation of the peptide transporter protein TAP-1 and loss of expression of the immunodominant MART-1/Melan-A antigen. J Clin Invest 98: 1633-1641, 1996.

81. Wherry EJ: T-cell exhaustion. Nat Immunol 12: 492-499, 2011.

82. Schatton T, Schütte U, Frank NY, Zhan Q, Hoerning A Robles SC, Zhou J, Hodi FS, Spagnoli GC, Murphy GF and Frank MH: Modulation of T-cell activation by malignant melanoma initiating cells. Cancer Res 70: 697-708, 2010.

83. Solana R, Casado JG, Delgado E, DelaRosa O, Marín J, Durán E, Pawelec G, Tarazona R: Lymphocyte activation in response to melanoma: interaction of NK-associated receptors and their ligands. Cancer Immunol Immunother 56: 101-109, 2006.

84. Jandus C, Bioley G, Speiser DE and Romero P: Selective accumulation of differentiated FOXP $3{ }^{+} \mathrm{CD}^{+}{ }^{+} \mathrm{T}$-cells in metastatic tumor lesions from melanoma patients compared to peripheral blood. Cancer Immunol Immunother 57: 1795-1805, 2008

85. Gorelik L and Flavell RA: Immune-mediated eradication of tumors through the blockade of transforming growth factor- $\beta$ signaling in T-cells. Nat Med 7: 1118-1122, 2001

86. Nicolaou A, Estdale SE, Tsatmali M, Herrero DP and Thody AJ: Prostaglandin production by melanocytic cells and the effect of $\alpha$-melanocyte stimulating hormone. FEBS Lett 570: 223-226, 2004

87. Hirano F, Kaneko K, Tamura H, Dong H, Wang S, Ichikawa M, Rietz C, Flies DB, Lau JS, Zhu G, et al: Blockade of B7-H1 and PD-1 by monoclonal antibodies potentiates cancer therapeutic immunity. Cancer Res 65: 1089-1096, 2005. 